
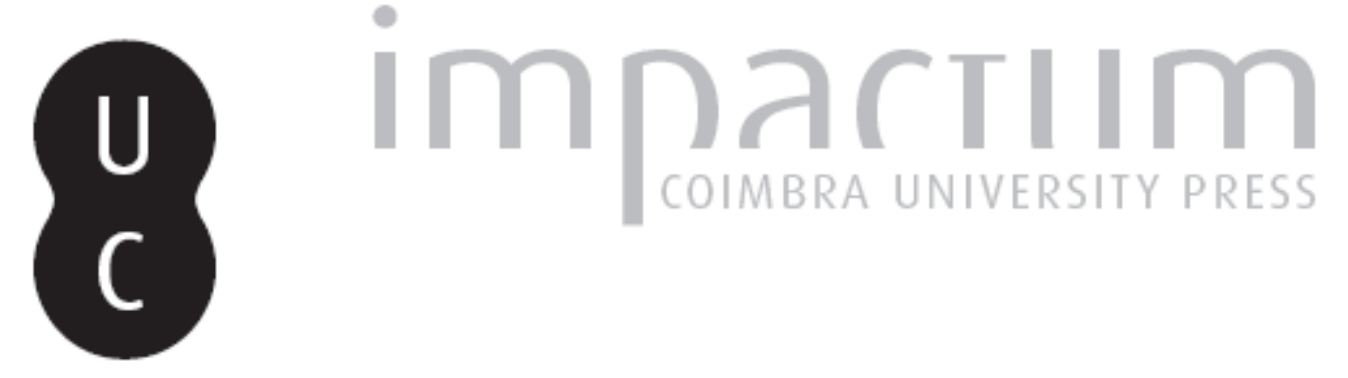

\title{
Aspectos do mundo funerário romano na Beira Interior: as estruturas funerárias monumentais da Quinta da Fórnea II (Belmonte): uma primeira abordagem
}

Autor(es): $\quad$ Santos, Filipe João Carvalho dos; Carvalho, Pedro C.

Publicado por: Faculdade de Letras da Universidade de Coimbra

URL persistente:

URI:http://hdl.handle.net/10316.2/37768

DOI:

DOI:http://dx.doi.org/10.14195/1647-8657_47_7

Accessed : $\quad$ 26-Apr-2023 16:17:57

A navegação consulta e descarregamento dos títulos inseridos nas Bibliotecas Digitais UC Digitalis, UC Pombalina e UC Impactum, pressupõem a aceitação plena e sem reservas dos Termos e Condições de Uso destas Bibliotecas Digitais, disponíveis em https://digitalis.uc.pt/pt-pt/termos.

Conforme exposto nos referidos Termos e Condições de Uso, o descarregamento de títulos de acesso restrito requer uma licença válida de autorização devendo o utilizador aceder ao(s) documento(s) a partir de um endereço de IP da instituição detentora da supramencionada licença.

Ao utilizador é apenas permitido o descarregamento para uso pessoal, pelo que o emprego do(s) título(s) descarregado(s) para outro fim, designadamente comercial, carece de autorização do respetivo autor ou editor da obra.

Na medida em que todas as obras da UC Digitalis se encontram protegidas pelo Código do Direito de Autor e Direitos Conexos e demais legislação aplicável, toda a cópia, parcial ou total, deste documento, nos casos em que é legalmente admitida, deverá conter ou fazer-se acompanhar por este aviso.

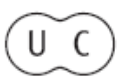




\section{CONIMBRIGA}

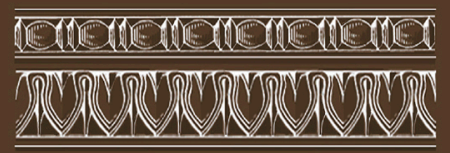

INSTITUTO DE ARQUEOLOGIA

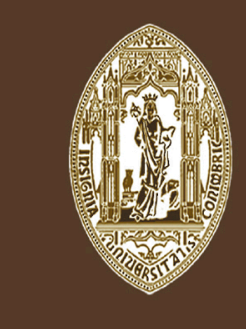

VOLUME XLVII - 2008

FACULDADE DE LETRAS UNIVERSIDADE DE COIMBRA 
Filipe JoÃo Carvalho dos SAntos

Arqueólogo dos quadros permanentes da empresa Arqueohoje

santos.philipe@gmail.com

Pedro C. Carvalho

Instituto de Arqueologia. Faculdade de Letras da Universidade de Coimbra

pedrooak@gmail.com

ASPECTOS DO MUNDO FUNERÁRIO ROMANO NA BEIRA INTERIOR. AS ESTRUTURAS FUNERÁRIAS MONUMENTAIS DA QUINTA DA FÓRNEA II (BELMONTE): UMA PRIMEIRA ABORDAGEM

"Conimbriga" XLVII (2008) p. 127-143

Resumo: Apresentam-se as estruturas de um mausoléu em forma de altar com pulvinos, descobertas em recentes escavações efectuadas no lugar da Quinta da Fórnea II (Belmonte). O achado deste tipo de monumentos funerários, possivelmente alto-imperiais, destaca-se pela singularidade ou ineditismo que constitui - em toda a região da Beira interior - a sua identificação no terreno, conservados ainda parcialmente in situ. A integração num espaço funerário mais amplo, a possível associação a uma villa e a proximidade em relação a uma importante via, reforçam a importância destas estruturas no quadro dos estudos sobre a ocupação romana do interior norte da prouincia Lusitania.

ABSTRACT: Des fouilles récentes menées à Quinta da Fórnea II (Belmonte) ont mis au jour des structures d'un mausolée ayant la forme d'un autel aux pulvini. La découverte de ce type de monuments funéraires (probablement haut-impériaux) dans la région de la Beira Interior se fait remarquer soit par la singularité soit par la nouveauté dont ils sont apperçus sur le terrain, conservés encore partiellement in situ. L'intégration dans un espace funéraire plus vaste, l'association tout à fait possible à une villa et la proximité par rapport à une importante voie renforcent l'importance de ces structures dans le cadre des études sur l'occupation romaine de l'intérieur nord de la provincia Lusitania. 
(Página deixada propositadamente em branco) 


\title{
ASPECTOS DO MUNDO FUNERÁRIO ROMANO NA BEIRA INTERIOR
}

\author{
As estruturas funerárias monumentais \\ da Quinta da Fórnea II (Belmonte): \\ uma primeira abordagem
}

\section{Nota introdutória}

No âmbito dos trabalhos de execução do Aproveitamento Hidroagrícola da Cova da Beira, concretamente no troço localizado entre o PK 2+260 e 2+300 da conduta C14 (Rede de Rega T6, Belmonte), foram identificadas - em meados de 2006 - as ruínas de estruturas monumentais datáveis do período romano.

Não obstante se tratar, do ponto de vista arqueológico, de uma área extremamente sensível - na qual se podiam observar alguns núcleos dispersos com materiais romanos à superfície, tendo sido inclusivamente já escavada parte de uma necrópole com sepulturas de incineração ${ }^{1}$ - o acompanhamento arqueológico, neste lugar específico da frente de obra, não terá sido o mais apropriado, tendo a abertura da vala para instalação do canal de regra originado a destruição parcial das referidas estruturas romanas.

Face ao sucedido, e dada a natureza dos vestígios descobertos, foi decidido superiormente pôr em prática um plano de trabalhos arqueológicos que visasse obter respostas efectivas para algumas das questões que este achado desde o início suscitou. Assim, para além de se procu-

1 Trabalhos realizados em 1997 para a extinta JAE (Junta Autónoma de Estradas, hoje EP) pela empresa Arqueohoje, no âmbito do projecto de Execução do Itinerário Principal 2 (actualmente designada por A 23) - lanço entre Belmonte Norte e Belmonte Sul. 
rar averiguar o verdadeiro impacte da empreitada em curso sobre os vestígios arqueológicos, importava essencialmente a caracterização e contextualização precisa dos mesmos.

Iniciadas as escavações neste lugar, e perante as primeiras ocorrências observadas, desde logo foi possível comprovar a veracidade de uma das interpretações inicialmente aventadas: os restos descobertos correspondiam a estruturas monumentais de carácter funerário, localizadas em área de necrópole mais vasta, uma vez que já se tinham encontrado (e escavado) três sepulturas de incineração nas imediações.

Este plano de trabalhos - que contemplou a escavação de uma área substancial - foi promovido pela Direcção Regional de Agricultura e Desenvolvimento Regional. A execução dos mesmos ficou a cargo da firma Arqueohoje ${ }^{2}$. A direcção científica dos trabalhos arqueológicos foi da responsabilidade de um dos signatários (Filipe Santos).

\section{Localização geográfica e contextualização arqueológica}

O sítio da Quinta da Fórnea II localiza-se no concelho e freguesia de Belmonte, distrito de Castelo Branco ${ }^{3}$. Situado no complexo litológico denominado por "Granito das Beiras", caracterizado pelos granitos porfiróides de grão grosseiro, este lugar posiciona-se em terrenos hoje aráveis, numa zona de vale - na base da encosta oriental da serra da Boa Esperança - e a escassos metros da Estrada Nacional 345 (junto à sua berma direita, no sentido Caria/Belmonte) (Est. I).

A construção monumental agora descoberta, como antes referimos, ocupará parte da área de uma necrópole. Esta, delimitada aparentemente por muretes, comportaria ainda uma zona com outro tipo de sepulturas de incineração, estruturadas em pequenas fossas, e datadas possivelmente do período alto-imperial, atendendo aos materiais descobertos durante a sua escavação em 1997 (Foto. 5).

A presença desta necrópole relacionar-se-á, forçosamente, com um contexto habitacional coevo situado relativamente próximo. À partida,

2 Arqueohoje, Lda., Rua da Escola, Lote 9, Loja 2, Santa Eulália, 3500-682 Viseu.

3 Apresenta as seguintes coordenadas: M.266386.72, P.374165.49, com valor de cota absoluta - retirado num ponto central do local - de $499.80 \mathrm{~m}$.

Conimbriga, 47 (2008) 127-143 
tanto poderá vincular-se com a villa da Fórnea I (sabemos hoje que a Quinta da Fórnea I, é, efectivamente, uma villa agrícola $)^{4}$, localizada a cerca de $400 \mathrm{~m}$ para SO, como com a possível villa das Marradas (= Quinta da Fórnea III), situada a cerca de duas ou três centenas de metros mais a nordeste, ou mesmo com ambos os núcleos residenciais ${ }^{5}$. No entanto, face à datação até agora atribuída à Quinta da Fórnea I (sítio ocupado durante o Baixo Império e cuja construção poderá remontar ao séc. II d.C. - e, assim sendo, posterior ao período de construção que propomos para a estrutura em estudo) e ao carácter não monumental deste mesmo sítio (pouco condizente com a monumentalidade revelada pelos restos da construção da Quinta da Fórnea II), parece-nos mais provável a sua relação com a referida villa das Marradas - mais próxima da necrópole e com vestígios à superfície reveladores de um maior requinte construtivo ${ }^{6}$.

A sua provável localização junto a uma importante via imperial, e possivelmente próximo da sua berma direita (para quem a percorria vindo de sul), como veremos adiante, parece de algum modo reforçar ainda mais a ligação desta necrópole com a mencionada villa das Marradas (= Quinta da Fórnea III) (Est. I).

\section{Metodologia}

A intervenção arqueológica na Quinta da Fórnea II desenrolou-se ao longo de duas campanhas levadas a cabo em 2007 - a primeira decorreu entre os dias 10 e 25 de Julho; a segunda, entre os dias 22 de Outubro e 26 de Novembro.

Após o reconhecimento prévio do local, e de acordo com as especificidades do próprio sítio e dos vestígios ainda preservados, resolvemos materializar no terreno uma malha quadriculada, com 2 × 2 m de lado, de modo a abarcar a totalidade das estruturas visíveis. Esta área

4 Estação arqueológica actualmente em fase de escavação - processo a cargo da empresa Arqueohoje e dirigido no terreno por Filipe Santos - com vista ao seu estudo e musealização.

5 Para a caracterização e contextualização destes sítios arqueológicos, cf. CARVALHO, 2007: 165-166 e 473 ss.

6 Amontoados junto à casa da actual quinta podem observar-se vários elementos arquitectónicos, alguns dos quais de muito boa feitura, como por exemplo, uma base de coluna com fino cordão gravado em baixo relevo. 
quadriculada, que conheceu alargamentos sucessivos impostos pelos resultados da própria intervenção, foi sendo implantada mediante o recurso a uma estação total, encontrando-se, portanto, devidamente georeferenciada (com base no sistema de coordenadas Datum 73). A área seleccionada para ser intervencionada correspondeu sensivelmente a um rectângulo, com uma orientação genérica SO/NE, de 17 x 24 m, onde no seu eixo menor - das abcissas (x) - se atribuíram letras (de A`a $\mathrm{H}$ ), e ao eixo maior - das ordenadas (y) - números (de 1`a 11). No final, a área escavada totalizou $240 \mathrm{~m} 2$ (Est. II).

A escavação arqueológica desenvolveu-se sempre em área (open area), permitindo deste modo uma visão global sobre todas as realidades estratigráficas contemporâneas, facilitando assim a sua compreensão. O registo das sequências estratigráficas fez-se basicamente por sucessivos planos, efectuando-se ainda a partir dos próprios perfis que foram delineando os limites da área intervencionada (Est. III). Durante a escavação procedeu-se à identificação, delimitação em extensão e decapagem sucessiva dos vários estratos identificados, tendo-se removido os mesmos - sempre que possível - pela ordem inversa à da sua deposição. A especificidade deste tipo de intervenção, bem como da própria natureza dos depósitos identificados e dos materiais arqueológicos existentes, permitiu - de forma complementar à escavação manual - a utilização de meios mecânicos. Esta forma de intervenção, levada a cabo de modo perfeitamente controlado, permitiu uma execução rápida e eficiente dos trabalhos, sem perda alguma do rigor científico exigido.

As duas campanhas de escavação contaram com a participação de vários profissionais de arqueologia que souberam estar à altura da intervenção. Sem eles, e sem a sua competência e dedicação (que se estendeu mesmo por horários extra laborais), o resultado final deste trabalho não teria sido possível 7 .

\section{Resultados: contextos estratigráficos, estruturas e materiais}

O sítio arqueológico agora intervencionado destaca-se, desde logo, por constituir um dos pouquíssimos exemplos de mausoléus em forma

7 O nosso reconhecido agradecimento aos colegas António Felgueiras, Carla Alegria, Edgar Figueira, Eugénio Mendes, Helena Barranhão, Rui Barbosa, Rui Carvalho, Rui Silva, Sónia Cravo e Óscar Rodrigues. 
de altar (com pulvinos) recuperado in situ (nem que seja parcialmente) em toda da Hispania ${ }^{8}$. É certo que nada se terá encontrado dos corpos de "cota positiva" relacionados com as estruturas monumentais funerárias propriamente ditas. O que persistiu no tempo, e sobreviveu em parte à destruição provocada pela recente empreitada, corresponderá em exclusivo aos alicerces das mesmas (Est. II e Fot. 1 e 3). Mas tal não diminuirá a relevância deste achado, até porque, para além dos referidos restos in situ, sobreviveram alguns elementos arquitectónicos que compunham a estrutura principal dessas construções, os quais encontrámos dispersos pela área escavada (Fot. 2). E embora se trate de elementos derrubados, estes poderão contribuir decisivamente para um melhor entendimento dos corpos edificados aos quais pertenciam.

Ainda assim, e apenas pela análise dos alicerces, que chegam a atingir 1,80 $\mathrm{m}$ de altura, construídos em silharia de granito toscamente esquadriada mas de dimensões regulares ${ }^{9}$, podemos imaginar a imponência que estas construções teriam. As estruturas in situ, em plano, revelam a presença de dois corpos adossados, ambos desenhados em função de um eixo longitudinal orientado a sudoeste / nordeste (Est. VI e III). O corpo ou edifício maior apresenta uma planta sub-rectangular, com $5.5 \mathrm{~m}$ de comprimento por $4.65 \mathrm{~m}$ de largura; o segundo, mais pequeno, de planta quadrangular, apresenta c. $4.25 \mathrm{~m}$ de lado, sendo, em termos de cronologia relativa, posterior ao primeiro, uma vez que, estratigraficamente, foi possível verificar que a sua construção originou um corte parcial na vala de fundação do lado nordeste do corpo maior.

Dentro dos aspectos técnico-construtivos, podemos também salientar que ambas as estruturas foram construídas mediante a prévia abertura de valas de fundação (Est. III e Foto 3). Estas perfuraram níveis sedimentares, tendencialmente arenosos e de origem coluvionar, até atingirem o substrato de base. Verificou-se ainda que os construtores, logo após a abertura das fundações, colocaram de forma sobreposta no interior dos caboucos um total de quatro monólitos - reforçados ainda mais do lado ocidental do edifício maior por um possante enrocamento

8 Até ao momento, aparentemente, conhecem-se em toda a Hispania apenas mais dois outros casos, mas nenhum na prouincia Lusitania: cf. Beltrán, 2004: 127.

9 A matéria-prima utilizada nos blocos das fundações é local e compõe-se, exclusivamente, por elementos de granito cinzento de grão grosso (granito comummente designado por "dente de cavalo"). 
de base ${ }^{10}$ - até ser atingida a cota pretendida ${ }^{11}$. E seria a partir do topo do último destes monólitos que se desenvolveria a construção a "cota positiva" do(s) edifício(s), muito provavelmente iniciada, em ambos os casos, por um soco moldurado. A restante construção, e o grosso do(s) edifício(s) - seria formada por grandes blocos aparelhados (opus quadratum) que encontrámos dispersos pela área escavada; e as paredes assim levantadas, aparentemente sem qualquer argamassa de ligação entre os seus blocos constituintes, seriam possivelmente rematadas por uma cornija de coroamento (cf., a título de exemplo, Est. IV, 11, a azul) ${ }^{12}$.

No que respeita aos materiais arqueológicos exumados, aparentemente coevos das construções em apreço, estes destacam-se fundamentalmente por serem quase residuais. Durante toda a escavação, apenas foi possível recolher escassos fragmentos informes de cerâmica, pequenos pedaços de vidro e um ou outro elemento metálico (eventualmente relacionados com as junções entre silhares). Os fragmentos cerâmicos recolhidos parecem na sua generalidade integrar as produções locais e/ou regionais das vasilhas de uso comum, feitas a torno e com superfícies - vagamente alisadas - de tonalidade castanho-alaranjada ou, em menor número, cinzentas. Embora estas cerâmicas não tenham sido encontradas directamente associadas aos contextos originais de depósito, nem seja possível restituir-lhes as formas, dado o seu carácter extremamente fragmentado, é possível que algumas delas se relacionem directamente com o conjunto de peças que acompanhavam, nas câmaras sepulcrais, as próprias incinerações. Entre os materiais cerâmicos recolhidos ainda uma particular referência para quatro fragmentos informes de terra sigillata hispânica - contudo, e uma vez que nenhum deles se encontrou associado a contextos seguros de construção ou fun-

$10 \mathrm{O}$ restante espaço entre a parede da vala de fundação e os silhares encontravase preenchido com pedras graníticas, angulosas, de pequenas e médias dimensões.

11 A cota de topo deste elemento é muito aproximada à do terreno actual, encontrando-se - como se poderá observar no corte apresentado - muito à superfície. Refirase ainda que o topo do alicerce da estrutura quadrangular apresenta uma diferença de cota, em relação ao do edifício maior, em torno dos - 0.15 m. Esta diferença não deixará de ser significativa, face à regularidade de todos estes elementos em cada uma das estruturas.

12 Veja-se, não só a este propósito, mas também em relação às dimensões e à sua disposição espacial, os monumentos funerários de Trion, em Lyon (FELlague, 2001: 357). 
cionamento do conjunto monumental descoberto, não pode ser relevada aqui a sua função como índices cronológicos.

Desde logo, esta não associação de materiais datáveis a contextos estratigráficos primários, relacionáveis com o processo de construção e o período de ocupação do local, resulta do facto destes contextos terem primado praticamente pela sua ausência. Com efeito, para além dos enchimentos das valas de fundação do conjunto monumental (valas preenchidas em grande parte com pedras) e do grande nível de derrube (formado por elementos arquitectónicos soltos), os restantes estratos identificados correspondem quase na sua totalidade a níveis de pósabandono (Est. III).

Mas voltemos às questões de ordem construtiva: um dos aspectos essenciais desta intervenção foi o de ter permitido recuperar algumas dezenas de elementos arquitectónicos - é certo que muitos deles fragmentados - pertencentes às construções originais. A recuperação destes elementos, por sua vez, permitiu-nos constatar a utilização de dois tipos de granito. Por um lado, identificaram-se blocos em granito de grão grosso, semelhantes - embora perfeitamente esquadriados - aos que foram utilizados nas fundações; por outro, reconheceram-se também alguns elementos de granito de grão fino e com tonalidade mais clara ou mesmo amarelada.

É possível que cada um destes distintos granitos pertença, especificamente, a cada uma das construções: uma delas poderia ter sido construída com o granito local, de grão grosso, enquanto que a outra comportaria o granito de grão fino, oriundo de outra zona desta região. Esta diferenciação poderá relacionar-se com a função específica de cada um dos corpos construtivos, surgindo o altar individualizado em relação à câmara funerária; ou então, relacionar-se-á com dois mausoléus distintos, resultando também de dois momentos construtivos diferentes ${ }^{13}-\mathrm{e}$ mesmo que estes dois corpos façam parte de um mesmo edifício, parece-nos ainda lícito equacionar a possibilidade de o corpo mais pequeno ter sido construído de forma a ampliar um primeiro espaço sepulcral, optando-se então na nova construção por recorrer a um outro

13 Poderemos mesmo imaginar, como hipótese a ponderar melhor futuramente, a presença não só de um mausoléu coroado por pulvini, mas também de um outro (neste caso, correspondendo ao corpo mais pequeno) que recorresse a uma solução com arco, à semelhança dos monumentos torriformes com aedicula, atestados na Gália (SousKIASSIAN, 2006: 474) ou na Hispânia (CANCELA, 2006: 215). 
tipo de granito, mais fino. A partida, poderíamos ainda supor que estes dois tipos de granito foram utilizados em diferentes componentes deste(s) edifício(s), isto é, o granito de grão fino seria exclusivamente utilizado na feitura dos elementos arquitectónicos mais trabalhados ou decorativos. Todavia, comuns aos distintos granitos, encontra-se o mesmo tipo de elementos arquitectónicos, como sejam elementos de soco moldurados e cornijas. E este tipo de elementos, por sua vez, consoante o granito base que utilizam, apresentam uma nítida diferenciação ao nível da sua execução. Assim sendo, parece-nos difícil admitir atendendo a aspectos estéticos e ao respeito que se impõe numa construção "clássica" deste género - a possibilidade de terem funcionado em conjunto. $\mathrm{O}$ desenho das molduras, bem como as próprias espessuras de todos os elementos referidos, são nitidamente distintos, sendo também notório, como seria de esperar dadas as características da pedra, o maior cuidado colocado na feitura dos elementos de granito fino.

Dentro da amálgama de elementos pétreos que identificámos dispersos em escavação destacam-se dois pulvini: um praticamente inteiro e um outro fragmentado ${ }^{14}$ (Est. III e Fot. 4). Estes, feitos em granito de grão grosso, apresentam-se decorados nas faces externas através de motivos gravados em baixo-relevo - uma rosácea hexapétala, com botão central, marca as extremidades cilíndricas das peças, enquanto que um motivo formado por dois círculos concêntricos (e representando, provavelmente, uma pátera) preenche a extremidade oposta de uma delas; ambos os motivos são enquadrados por moldura, conseguida através do rebaixamento das superfícies. Estas duas peças da Quinta da Fórnea II, se atendermos aos aspectos formais e decorativos que apresentam, são muito semelhantes a outros exemplares conhecidos na Lusitania e, em particular, na região da Beira Interior ${ }^{15}$. Aliás, a Beira Interior parece

$14 \mathrm{O}$ pulvinus recolhido quase intacto - que seria o pulvinus esquerdo do monumentum - apresenta as seguintes dimensões: comprimento - 0,83 m; altura; espessura 0,40 m; altura máxima - 0,40 m; o diâmetro do círculo onde se inscreve a rosácea é de 0,27 m; o diâmetro da "pátera" é de 0,14 m.

15 Atendendo à tipologia criada por José Beltrán Forte e Luis Baena del Alcázar (1996), os pulvini da Quinta da Fórnea II pertencem ao tipo 2, caracterizando-se este por não apresentar rebordo saliente na base do pulvinus. A este tipo pertencem igualmente os exemplares da Caneca (Fundão) (EnCARnAÇão e CARVAlHo, 2006: 95) e da Torre dos Namorados (Fundão) (este último, ainda inédito, apresenta uma rosácea em espiral: comunicação pessoal de Carla Alegria, a quem agradecemos). 
constituir uma das regiões da Lusitania na qual os pulvini - e o tipo de mausoléus que estes encimavam - se encontram mais bem representados, à semelhança da própria capital provincial (BELTRÁN y BAENA, 1996: 114) ${ }^{16}$.

Se, em escavação, o achado destes pulvini permitiu de imediato interpretar o achado efectuado como restos de um mausoléu ou altar funerário monumental, também outros elementos arquitectónicos descobertos permitirão - em estudo mais aprofundado que reservamos para um futuro próximo - apresentar uma imagem mais aproximada e fidedigna do que seria este monumento. Entre esses elementos, e desde já, não queremos deixar de fazer particular referência a dois elementos de arco (de volta perfeita e recorte poligonal), encontrados num nível de revolvimento que preenchia o interior do corpo quadrangular e de menores dimensões (Est. V, 31B) (cf., a este propósito, nota 13). Depois, encontraram-se fragmentos de elementos cilíndricos, bem facetados e rebordo saliente (= D. 27, Est. V), com diâmetros semelhantes aos dos pulvini, que poderão corresponder ao prolongamento destes em profundidade, encimando e delineando as partes laterais do mausoléu. Para além destes, destacamos também um outro elemento, também de granito de grão fino, possivelmente relacionado com uma eventual porta (falsa?) pertencente à estrutura mais pequena (provavelmente construída, recordamos, com este género de granito): trata-se do elemento n. ${ }^{\circ} 28$ (Est. V, 28), isto é, parte de uma coluna que se encontraria adossada às paredes do edifício e que assentaria, por sua vez, num elemento moldurado, também de grão fino, identificado com o . $^{\circ} 1$ nos desenhos que apresentamos (Est. V, 1) ${ }^{17}$. Estes e outros integrariam o grupo de elementos verticais (colunas ou pilastras adossadas às paredes e/ou aos ângulos) que ritmavam e ornamentavam os corpos centrais (quadrangulares ou rectangulares) destes edifícios.

16 E na Beira interior não podemos deixar de realçar o numeroso e ainda pouco conhecido núcleo de pulvini encontrados na capital da civitas Igaeditanorum (Idanha-aVelha), composto por cerca de duas dezenas de peças (comunicação pessoal de José Cristóvão, a quem também agradecemos). Veja-se ainda, a título de exemplo, o conjunto de pulvini da região de Barcino, uma outra zona da Hispania onde é também particularmente numeroso este tipo de peças (RoDÀ, 2001: 26).

17 Como paralelos para a localização de elementos similares num edifício funerário monumental, ainda que neste caso concreto façam parte de uma falsa porta, apontamos o mausoléu, dito anónimo, de Thuburnica (Tunísia), correspondendo este, curiosamente, a um edifício torriforme com edícula (FERCHOU, 1986: 688). 


\section{Os mausoléus com pulvini}

Parece-nos importante iniciar este ponto com uma afirmação de Henner Von Hesberg (2006: 11): os edifícios funerários italianos serviram de modelo às obras da mesma natureza nas províncias ocidentais - e os mausoléus com pulvini não serão excepção.

A presença dos típicos mausoléus em forma de altar, coroados por pulvini, é relativamente comum a todo o Ocidente do Império, estendendo-se mesmo, obviamente com variantes regionais, às províncias danubianas e africanas (BELTRÁn y BAENA, 1996: 108; Molitor, 2006: 90-91). Embora apresente uma maior incidência em contextos urbanos, este tipo de sepulcros - que acolhiam as urnas cinerárias no seu interior - encontram-se também representados no conjunto das soluções funerárias monumentais de âmbito rural. Conhecem-se inúmeros achados avulso destas construções, reconhecidos essencialmente pelos principais elementos que os caracterizavam: os pulvini. Raras vezes, porém, podemos associar estes elementos aos próprios restos in situ dos edifícios aos quais pertenciam, como é o presente caso da Quinta da Fórnea.

Morfologicamente, este tipo de mausoléus - pelos exemplos conhecidos e em melhor estado de preservação ${ }^{18}$ - constitui uma solução arquitectónica que se assemelha em muito a um altar de grandes dimensões (GROS, 2000: 392 ss). Em termos cronológicos, por sua vez, é comummente aceite uma datação balizada genericamente entre o século I a. C. (para os primeiros modelos itálicos) e o século I d. C. Nas províncias do Império, como a Lusitania, estes monumenta teriam sido possivelmente introduzidos por colonos oriundos da Península Itálica e/ou por soldados veteranos a quem foram concedidas terras - assim, progressivamente, também nos espaços funerários, e mesmo nas zonas mais recônditas do Império, se fizeram sentir e podiam observar as marcantes influências culturais de Roma. Será plausível, portanto, uma atribuição augustana ou júlio-claudiana para muitos dos primeiros monumentos deste género conhecidos na prouincia Lusitania (BELTRÁN, 2004: 128). Estes mausoléus, na sua grande maioria, terão sido assim construídos durante o século I d.C. - como será o caso daqueles que gravitariam em torno da capital de civitas dos Igaeditani ou daqueloutros

18 Como o magnífico mausoléu de Calventio Quieto, próximo da villa dos Mistérios em Pompeia, ou de Munatius Faustus na Via dei Sepolcri (SAldíAs, 2003: 43). 
(como o da Quinta da Fórnea) que, mais a norte, constituiriam o lugar funerário de eleição das famílias detentoras das principais villae ${ }^{19}$.

\section{Conclusão}

O carácter singular das estruturas descobertas na Quinta da Fórnea II, e o próprio quadro espacial onde estas se integram, atribuem a este sítio arqueológico uma particular importância no contexto da ocupação romana do interior norte da Lusitania. Para além do ineditismo que constitui a identificação no terreno deste tipo de monumentos, cuja presença nesta região era já denunciada pelo achado de alguns pulvini dispersos, a sua integração num espaço funerário mais amplo, a sua possível associação a uma villa e a proximidade em relação a uma importante via, tornam toda a área arqueológica da Quinta da Fórnea, doravante, absolutamente incontornável no quadro dos estudos sobre a história antiga da Beira Interior.

Embora o grau de destruição das estruturas descobertas - e mesmo as características dos contextos estratigráficos onde se inserem - não permita delinear com outro rigor alguns dos aspectos construtivos - e cronológicos - que importaria aclarar, o registo efectuado durante a nossa escavação (e nomeadamente todo o conjunto de elementos arquitectónicos recolhido), é suficientemente vasto para justificar o continuar e o aprofundar desta primeira análise. A apresentação de uma proposta de restituição do(s) monumento(s), será seguramente um dos objectivos a fixar nesse nosso posterior e anunciado estudo. Mas tal obrigará, desde logo, que seja esclarecida a seguinte dúvida: as duas construções encontradas adossadas farão parte de um único mausoléu, com um corpo principal e uma estrutura "anexa avançada" ${ }^{20}$, ou constituirão

19 Esta associação, com as famílias mais ilustres das civitates do Norte interior da Lusitania, não pode deixar de ser estabelecida, à semelhança do que ocorre noutras regiões do Império, onde os grandes mausoléus, e sobretudo os torriformes de dois andares, se relacionam - quase em exclusivo - com membros das camadas sociais mais elevadas: magistrados, sacerdotes, cidadãos romanos, militares ou veteranos (GROS, 2000: 395; Molitor, 2006: 95).

20 Vejam-se, a título de exemplo, os mausoléus 12, 13 e 23 da Necrópole da Porta Romana de Ostia (Boschung, 1987: 113-114, Abb. 15) - existem casos em que os altares propriamente ditos surgem individualizados em relação à câmara funerária. 
dois monumenta distintos, embora com funções análogas, que se sucedem no tempo e traduzem uma ampliação do espaço sepulcral ${ }^{21}$. Por agora, e com a necessária segurança, poderemos apenas propor que todo este conjunto integraria um mesmo espaço funerário e que o corpo quadrangular, mais pequeno, foi construído posteriormente ao corpo subrectangular, de maiores proporções. Esta sucessão no tempo de ambas as construções, denunciada pela forma como os contextos estratigráficos associados se relacionam, não significa necessariamente, porém, a sua não contemporaneidade construtiva - apenas significa que um foi feito depois do outro, não existindo indicadores que permitam aferir a amplitude desse hiato. Assim como não foi possível isolar um contexto estratigráfico com índices de datação seguros que permitam atribuir às estruturas identificadas uma cronologia absoluta de construção. Seja como for, e atendendo à datação geralmente atribuída a este tipo de monumentos funerários, é muito possível que as estruturas da Quinta da Fórnea II datem genericamente do séc. I d. C.

Aliás, a sua eventual construção durante o período júlio-claudiano poderá encontrar-se relacionada com a primeira vaga de colonos que se instalaram e construíram as suas villae no interior norte da Lusitania, num momento seguinte à criação e delimitação augustana das civitates (CARVAlHo, 2007: 469 ss). É certo que não existem muitos indicadores, inclusivamente onomásticos, que revelem uma significativa presença de gentes oriundas de longínquas paragens nestas regiões a norte da civitas Igaeditanorum (Idem: 513 ss). Com efeito, o grosso da população teria profundas raízes autóctones, residindo sobretudo em quintas e casais rústicos dispersos pelos campos. Mas a ocupação romana destas paisagens da Beira Interior, e as mudanças nos contornos que as delinearam a partir de Augusto, não se terá operado sem a intervenção e o contributo exógeno. A edificação de algumas villae nesta região, e logo durante o Alto Império, constituirá um dos testemunhos mais expressivos da instalação de famílias emigradas (colonizadoras) e portadoras dos valores da romanidade. Assim como a construção, nos respectivos

21 Não podemos deixar de chamar à colação, a este propósito, os dois mausoléus adossados da villa da Quinta de Marim (Olhão) - de tipologia e cronologia distinta. Para além da grande edificação absidal, existe uma outra edificação contígua, quadrada e mais pequena (embora sem pulvini, veja-se a configuração e as dimensões desta), que Dennis Graen interpreta como "monumento sepulcral, talvez uma aedicula ou uma espécie de torre sepulcral pertencente ao primeiro período imperial” (GRAEN, 2007: 277). 
espaços funerários associados, dos mausoléus em forma de altar coroados por pulvini monumentais - marcos distintivos dos notáveis locais e investimento assinalável que também projectaria socialmente os seus promotores no seio das suas comunidades. Aliás, nestas regiões do interior norte da Lusitania, a autopromoção social de algumas famílias mediante a incorporação de modelos importados - parece revelar-se mais nos monumentos funerários (não só nos mausoléus, mas também em algumas placas funerárias de grandes dimensões) do que nas casas onde se vivia (ALARCÃO, 2006: 183).

O caso aqui abordado talvez seja, a este propósito, paradigmático, uma vez que poderá constituir um claro exemplo de uma nova realidade que começou a mostrar-se nos campos romanos da Beira Interior durante as primeiras décadas do séc. I d. C.: a instalação de uma villa, provida dos característicos urbana ornamenta, e a configuração, a cerca de $200 \mathrm{~m}$, do respectivo espaço funerário, no qual teriam lugar, sublinhe-se, não só um ou mais mausoléus, mas também outras sepulturas bem mais singelas, abertas simplesmente no saibro e com cinzas depositadas directamente em fossa, como aquelas registadas em anteriores escavações a escassas dezenas de metros do lugar agora escavado diferenças sociais, certamente, que se revelam também na natureza e organização dos espaços funerários deste mundo rural.

Um outro aspecto que deverá ser destacado, para finalizar, prendese com a possibilidade de o(s) mausoléu(s) da Quinta da Fórnea II ter(em) sido construído(s) exactamente junto à grande via imperial que, partindo de Emerita, e passando pela capital dos Igaeditani, se dirigia para norte, cruzando todo este território interior norte da prouincia Lusitania $^{22}$. Um dos troços desta via, que ligava em concreto as áreas de Caria e Centum Celas, é habitualmente delineado ao longo de um corredor natural que a actual Estrada Nacional 345 também percorre (Est. I) (Idem: 127 ss, Mapa 5). Ora, encontrando-se as estruturas em análise a cerca de $5 \mathrm{~m}$ dessa estrada, e partindo também do princípio de que os espaços funerários romanos procuravam visibilidade e a proximidade dos caminhos, parece-nos perfeitamente lícito imaginar, precisamente

$22 \mathrm{O}$ mesmo se passaria, sublinhe-se, mais a sul, com os prováveis mausoléus denunciados por pulvini - da Quinta da Caneca e da Torre dos Namorados (Fundão), situando-se ambos em lugares que bordejariam a via imperial (cf., CARVALHO, 2007: Mapa 5). 
junto à berma desse percurso, os principais monumentos funerários da villa da Fórnea III (= Marradas) e, assim sendo, admitir também que, ao menos neste troço em concreto, a actual estrada poderá em parte sobrepor-se à da época romana. A verificar-se este cenário, que contempla ainda a provável capital de civitas a três ou quatro milhas de distância, as silhuetas do(s) monumento(s) da Fórnea II constituiriam autênticos "marcos funerários", sóbrios mas monumentais, bem visíveis por todos os viandantes (tais como as inscrições que comportariam, na face voltada à estrada), enquanto que os núcleos rurais residenciais da Fórnea I e III se situariam um pouco mais recuados em relação à via imperial, a algumas centenas de passos. $\mathrm{O}(\mathrm{s})$ mausoléu(s) da Fórnea, constituiriam, no fundo, testemunho(s) de memórias ou de vidas passadas, cujos nomes a(s) lápide $(s)$ - hoje $\operatorname{perdida}(s)-\operatorname{procurava}(m)$ perpetuar.

\section{BIBLIOGRAFIA}

AlARCÃO, Jorge de (2006): "Os modelos romanos e os traslados provinciais na Lusitânia", El Concepto de lo Provincial en el Mundo Antiguo (Homenaje a la Professora Pilar León Alonso) (Vaquerizo, D., Murillo, J. F., Eds), Vol. I, Córdoba, p. 175-187.

BeltrÁn Fortes, José (2004): "Monumenta sepulcrales en forma de altar con pulvinos de los territorios hipanorromanos: revisión de materiales y estado de la cuestión", Archivo Español de Arqueología, vol. 75, CSIC, Madrid, p.101-141.

Beltrán Fortes, José y BAena del AlCÁzar, Luis (1996): "Pulvinos Monumentales de Mérida", Anas, 9, Museo Nacional de Arte Romano, Merida, p. 105-131.

Boschung, Dietrich (1987): "Die Republikanischen und Fruhkaiserzeitlichen Nekropolen vor den Torne Ostias", Romische Graberstrafen, Bayerische Akademie der Wissenschaften, Munchen, p. 111-124.

Cancela, Maria Luisa y Arellano, Ramirez (2006): "Los monumentos funerarios hispanos", L'architecture funéraire monumentale. La Gaule dans l'empire romain. Archéologie et Histoire de l'art, 24, p. 205-233.

Carvalho Pedro C. (2007): Cova da Beira, ocupação e exploração do território na época romana, Conímbriga / Anexos 4, Fundão-Coimbra.

CARvalho, Pedro C. e Encarnação, José d' (2006): "O monumento romano da Quinta da Caneca (Salgueiro, Fundão)”, Eburobriga, 4, p. 91-98.

Fellague, Djamila (2006): "Les mausolées de la necrópole de Trion a Lyon", L'architecture funéraire monumentale. La Gaule dans l'empire romain, Archéologie et Histoire de l'art, 24, p. 355-376.

FERCHIOU, Naidé (1986): "Le mausolée anonyme de Thuburnica", Mélanges de l’École Française de Rome - Antiquité, 98, n. ${ }^{\circ}$ 2, p. 665-705.

GraEn, Dennis (2007): "O sítio da Quinta de Marim (Olhão) na época tardo-romana e 
o problema da localização da Statio Sacra", Revista Portuguesa de Arqueologia, vol. 10, n. ${ }^{\circ}$, IPA, Lisboa, p. 275-288.

Gros, Pierre (2000): L'Architecture Romaine. Du début du IIIe siècle av. J.-C. à la fin du Haut-Empire, 2, Maisons, palais, villas et tombeaux.

Hesberg, Von Henner (2006): "Les modéles des edifices funéraires en Italie: leur message et leur reception", L'architecture funéraire monumentale. La Gaule dans l'empire romain, Archéologie et Histoire de l'art, 24, p. 11-39.

Molitor, Gabrielle-Kremer (2006) "L'architecture funéraire monumentale dans le Norique, la Pannonie et la Dacie", L'architecture funeráire monumentale. La Gaule dans l'empire romain. Archéologie et Histoire de l'art, 24 , p. 79-98.

RodÁ, Isabel (2001): "Barcelona. Desde su fundación hasta el siglo IV d.C.", De Barcino a Barciona (siglos I-VII), Los restos arqueológicos de la plaza del Rey de Barcelona, Ajuntament de Barcelona, p. 22-31.

SaldíAs, Mónica (2003): The Pompeian burial landscape after Sulla. A study of identity and social status before death, Cd paper in Classical Archaeology and Ancient History, University of Uppsala, Sweden.

Souskiassian, Georges (2006): "Les piles funéraires du Sud-Ouest", L'architecture funéraire monumentale. La Gaule dans l'empire romain. Archéologie et Histoire de l'Art, 24, p. 473-477. 
EsT. I

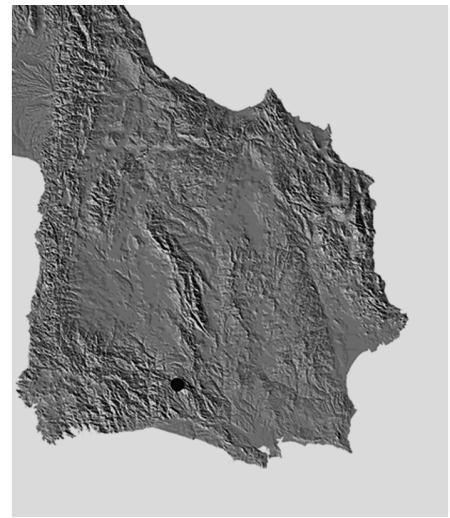

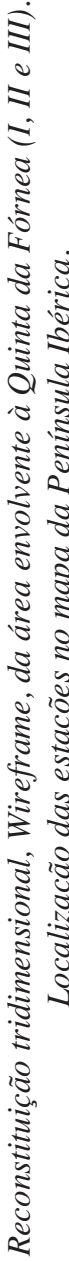

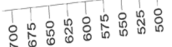

soдal 
EST. II

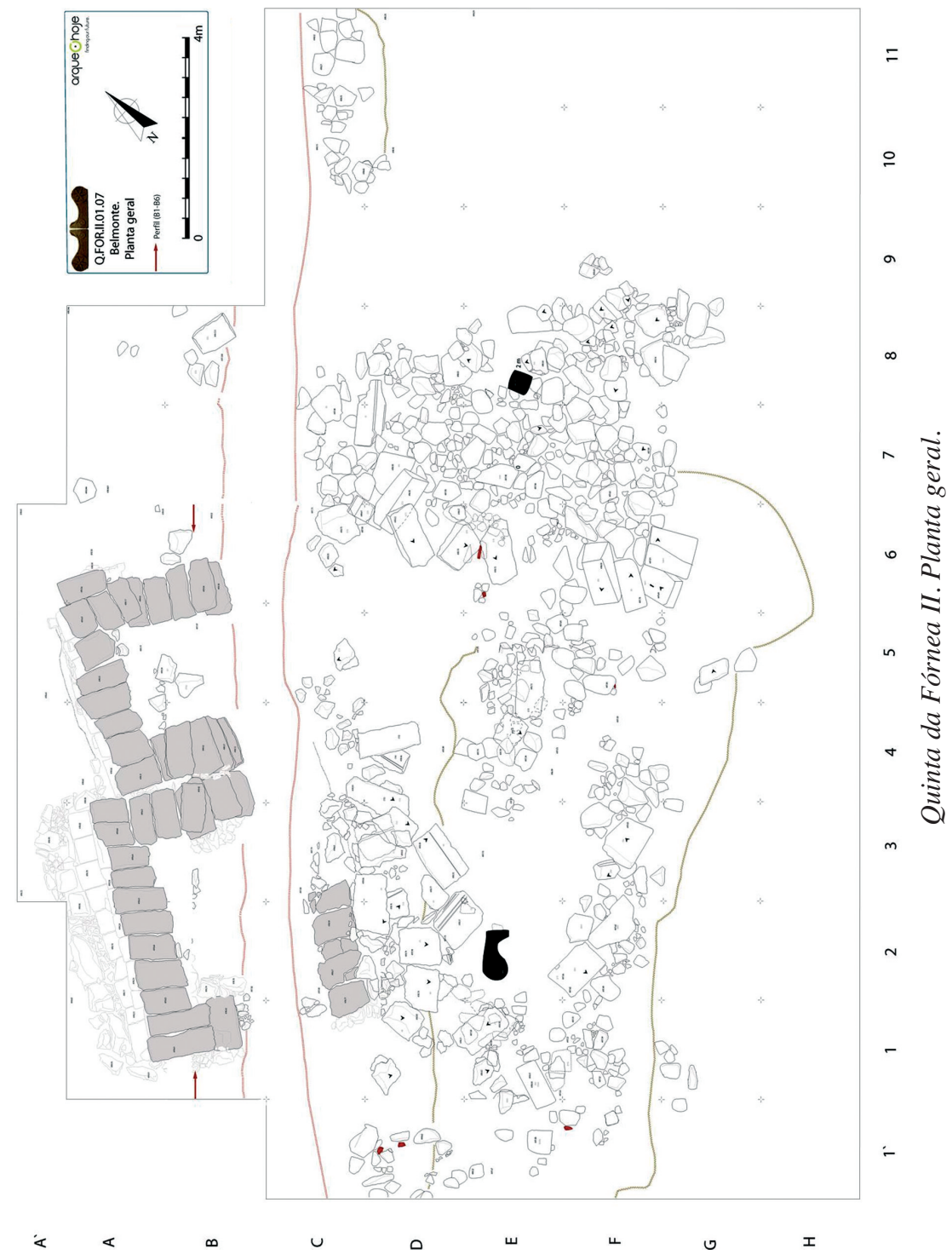


Est. III
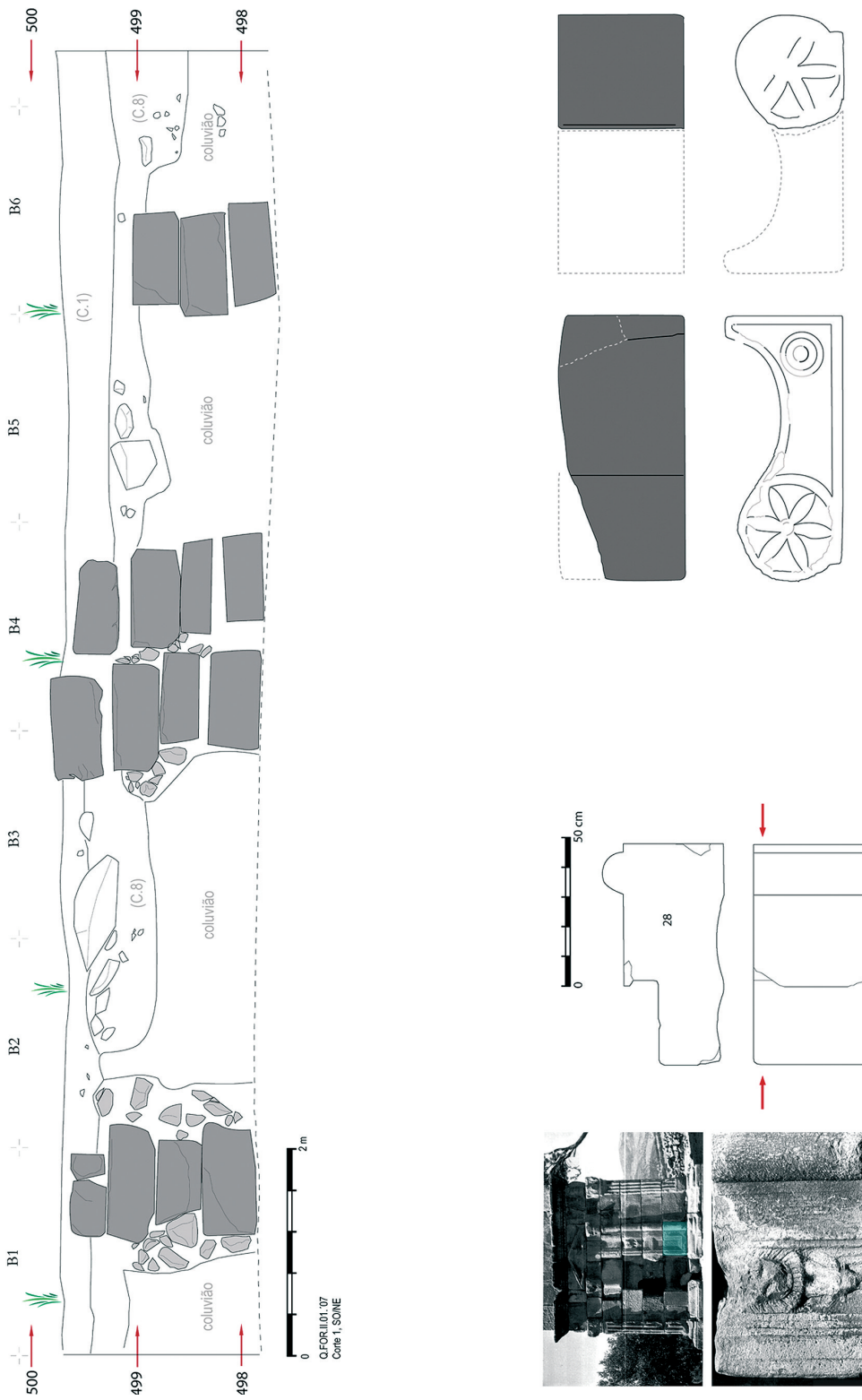

bे
0
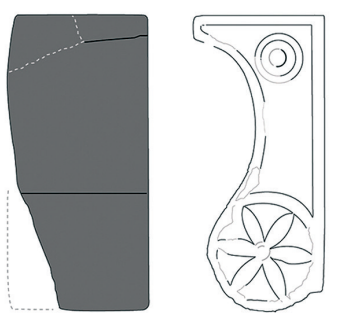

$\frac{3}{0}$

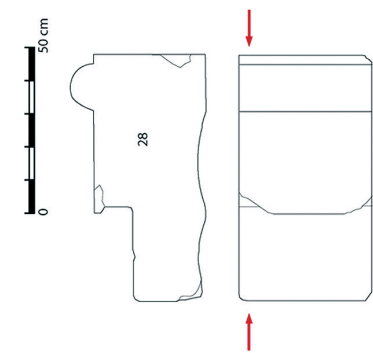

$\ddot{5}$

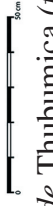

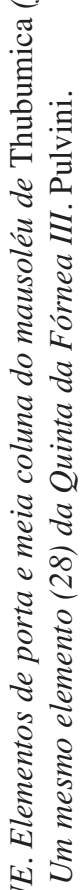

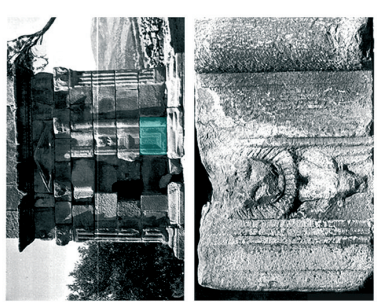

3
0
0
0
0
0
0
0
0
0
0
0
0
0
0
0 


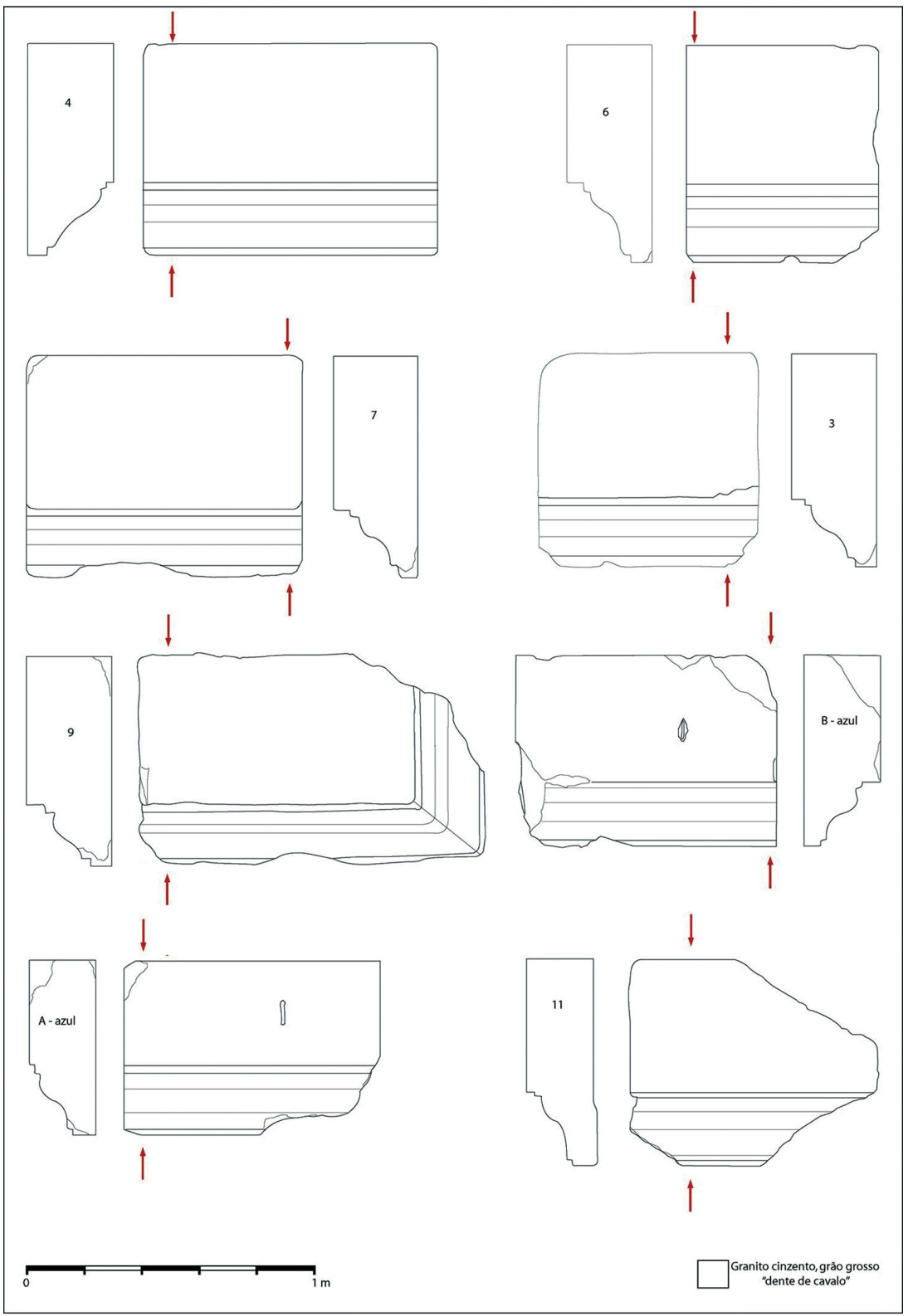

Elementos moldurados de base. Cornijas - (A-azul, 11). 
EsT. V

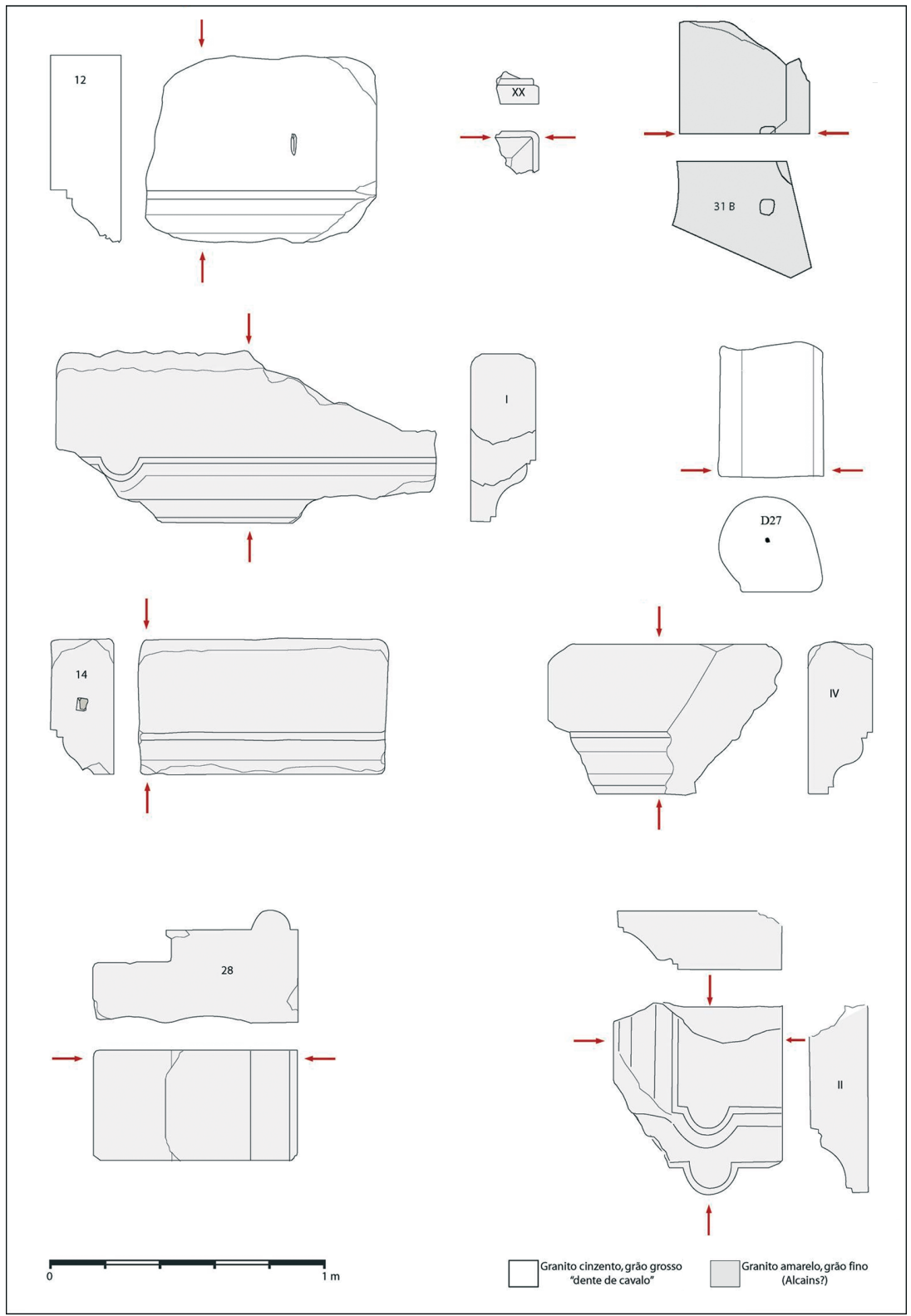

Elementos moldurados de base (I, II), cornijas $(12,14)$, de coroamento (D27), porta com pilastra adossada (28), arco (31B). 


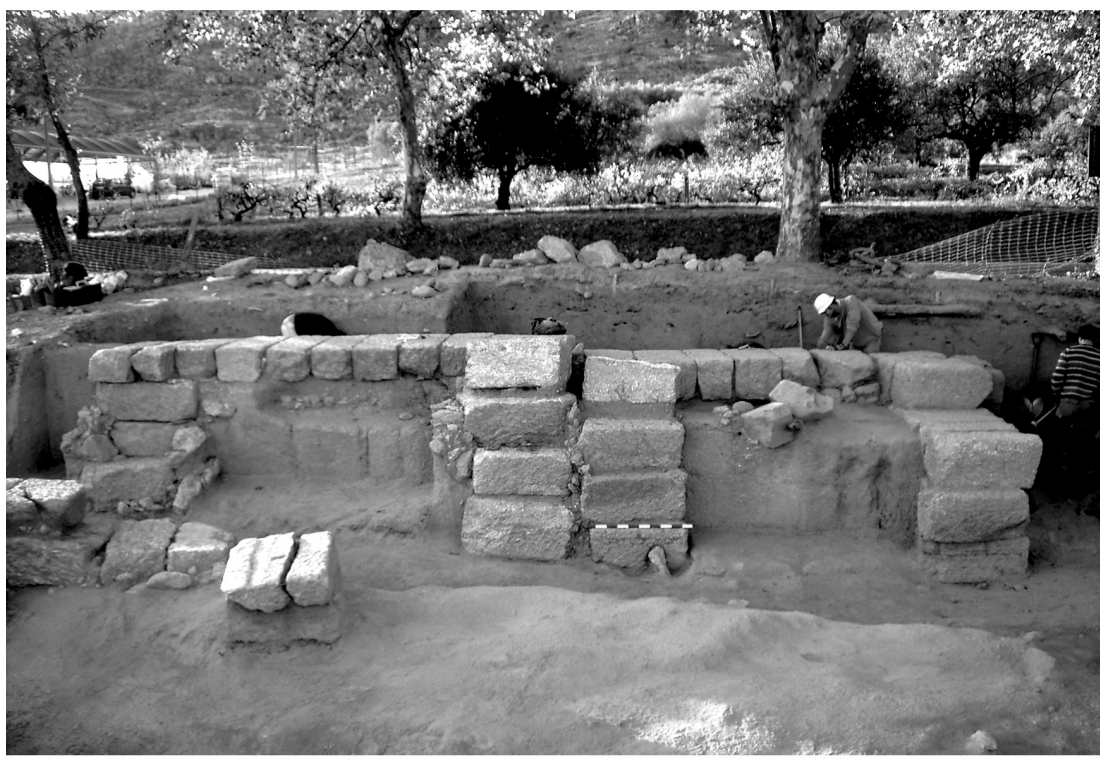

Fото 1

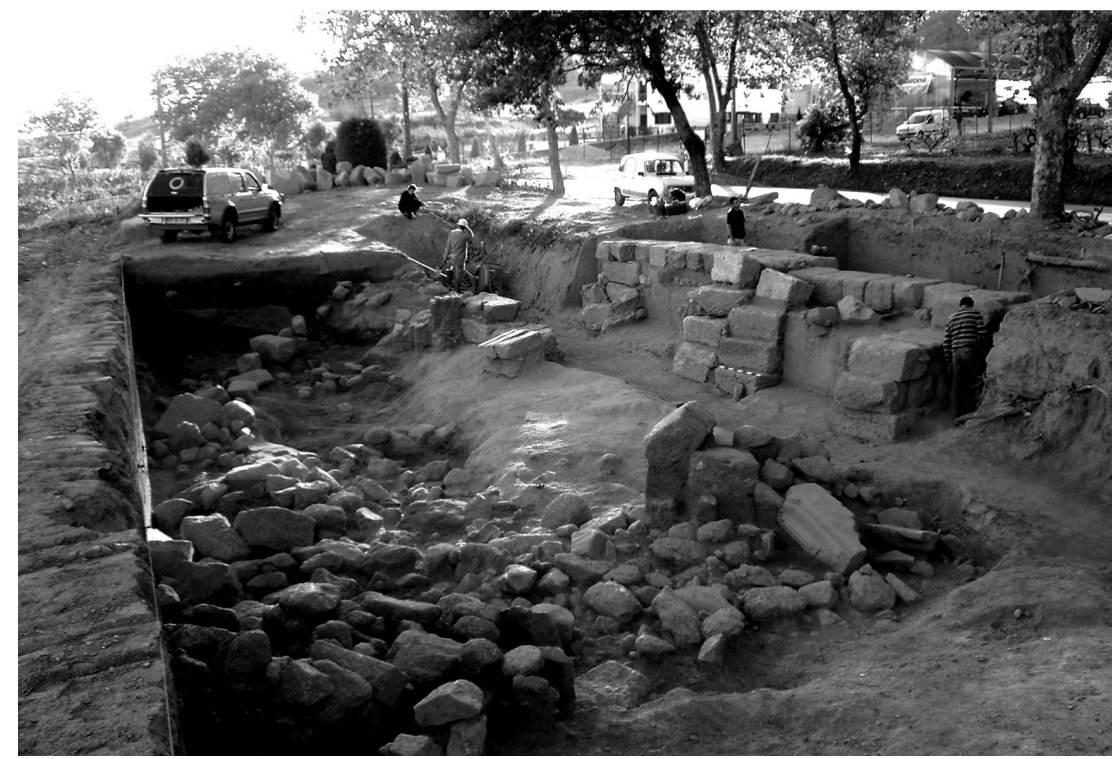

Fото 2 


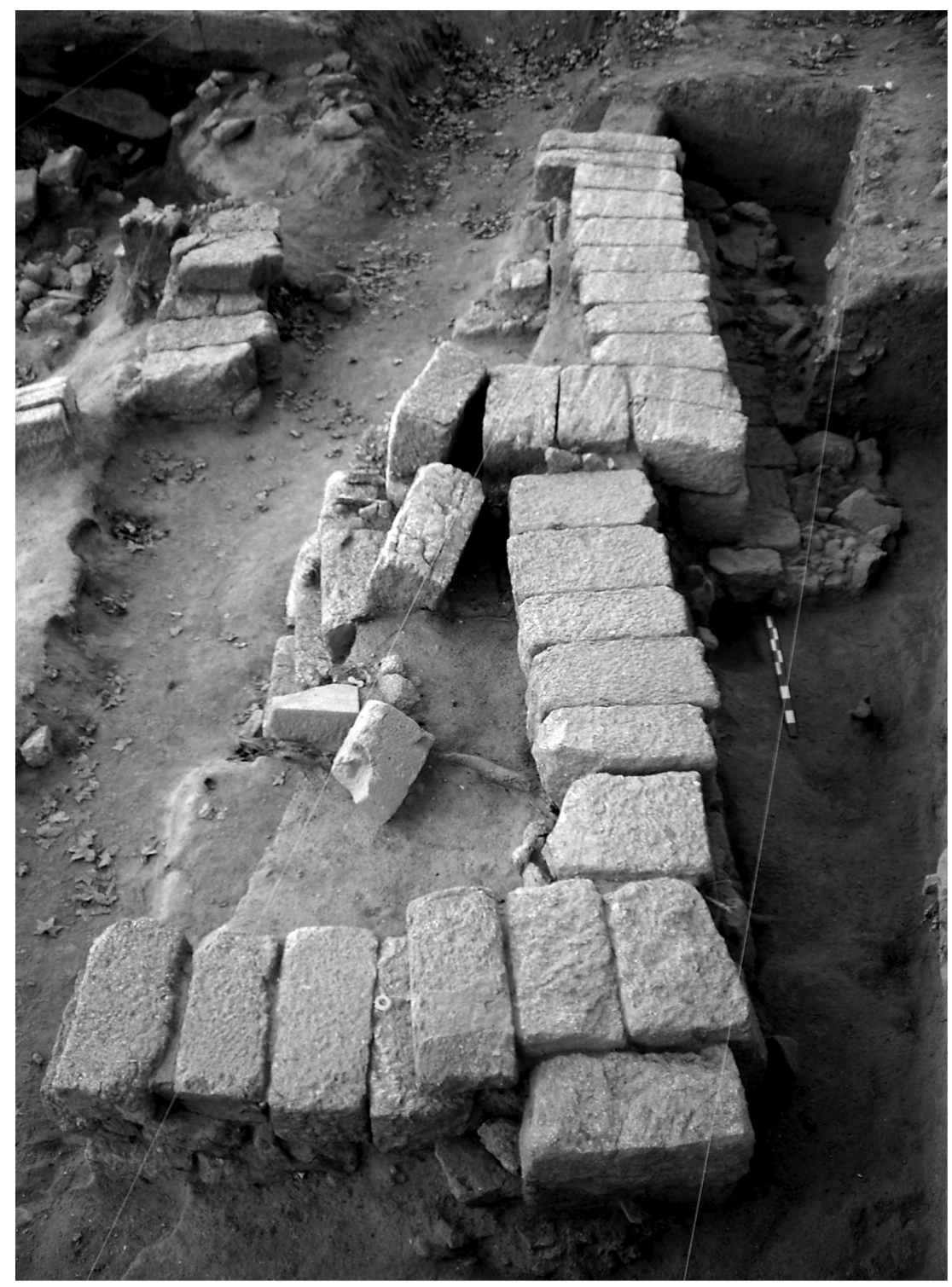

Fото 3 

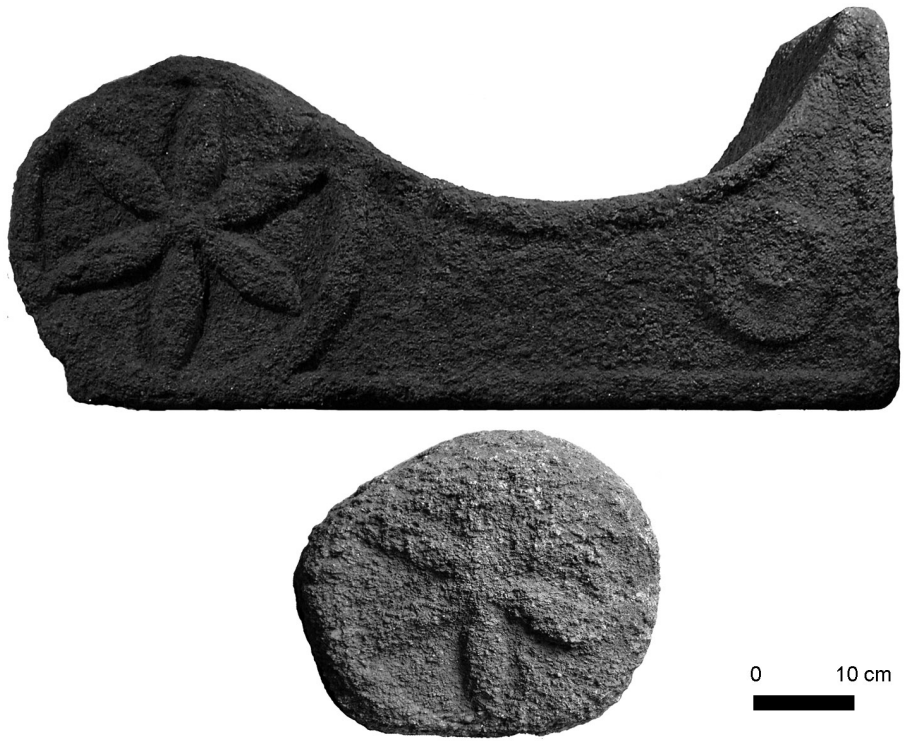

Fото 4

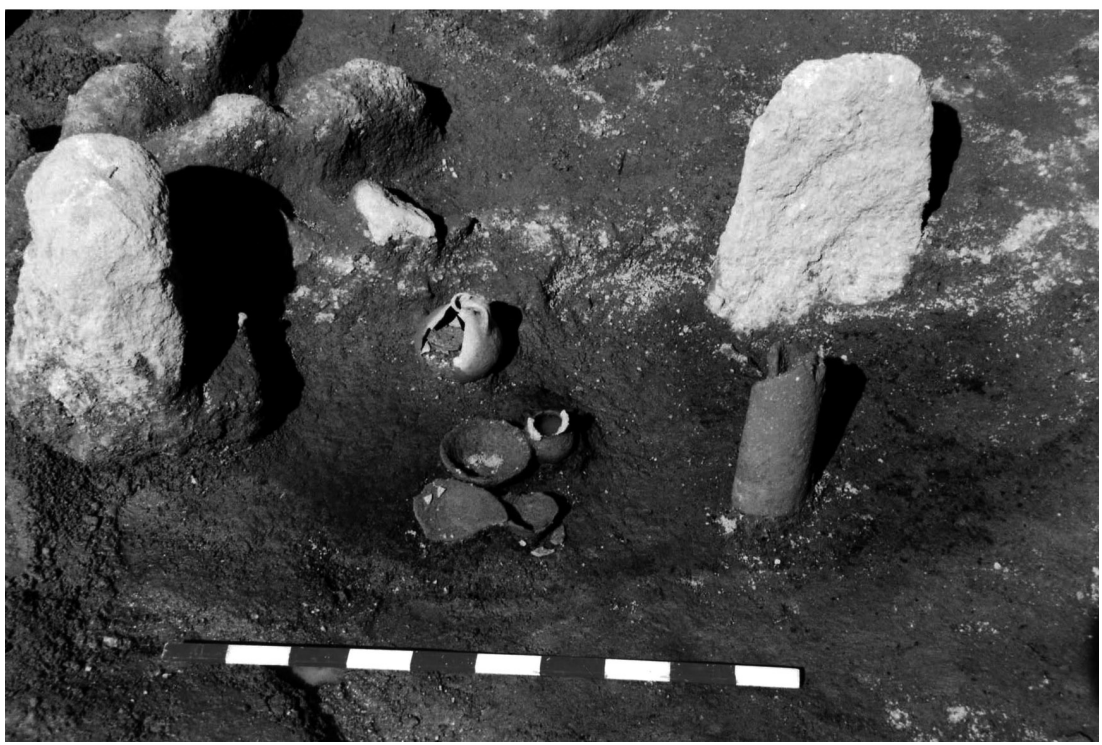

Fото 5 